\title{
From modal fallacies to a new argument for fatalism
}

\author{
Pedro Merlussi \\ https://orcid.org/0000-0003-4729-1143 \\ University of Campinas \\ Department of Philosophy \\ Campinas, $S P$ \\ Brazil \\ p.merlussi@gmail.com
}

\author{
Article Info: \\ CDD:160 \\ Received: 12.08.2019; Revised: 12.09.2019; Accepted: \\ 13.09.2019 \\ DOI: \\ http://dx.doi.org/10.1590/0100-6045.2019.V42N3.PM
}

\section{Keywords:}

Incompatibilism

Fatalism

Nodal fallacy

Actuality

Choice

Abstract: Do incompatibilist arguments, like some fatalist arguments, rest on modal fallacies? If Westphal (2012) is right, then one popular argument for incompatibilism van Inwagen's "First Formal Argument" - does rest on a modal fallacy. Similarly, Warfield (2000) claims that the standard modal formulation of the master argument for incompatibilism is a modal fallacy. Here, I refute both claims. Contra Westphal, I show that the mistake in van Inwagen's "First Formal Argument" is no modal fallacy. After that, I 
argue that Warfield's charge of modal fallacy can be easily avoided by using a plausible principle concerning actuality. Then, I show that this allows one to put forward a fairly simple argument for fatalism (the thesis that we aren't able to do otherwise from what we actually do).

\section{Introduction}

Fatalist arguments, if sound, have an incredible consequence. They try to establish that we are powerless to do anything other than what we actually do. Since this sort of conclusion strikes many of us as ultimately implausible, it wouldn't be too surprising if some fatalist arguments were invalid (well, at least to me). And it turns out that some of them are indeed simple modal fallacies. Here's a toy version of a traditional fatalist argument. Suppose that the proposition expressed by the sentence "I raise my hand" is true.

1. $\square($ I raise my hand $\supset$ I raise my hand)

2. I raise my hand

Thus,

3. $\square$ I raise my hand

If the conclusion were true, I would necessarily raise my hand. So I wouldn't do otherwise. But that's clearly invalid. 3 does not follow from 1 and 2 . (So much worse for the fatalist!)

Incompatibilists, on the other hand, are less ambitious. While the fatalist argues for the claim that we are powerless to do anything other than what we actually do, the incompatibilist makes a conditional claim; that, necessarily, if determinism is true, there's no free will (or at least no one has the ability to do otherwise). This claim doesn't seem as incredible as the 
fatalist one, for it relies on a contingent claim about the laws of nature: the laws of nature are universal in extent (e.g., they cover everything that happens in the world) and deterministic ${ }^{1}$. This claim about the laws was, once upon a time, the prevalent view about our world. It really seems as if science was telling us that determinism is true. If so, how can we act freely in a deterministic world?

Compatibilists make some room for free will in deterministic worlds. In fact, compatibilism was the received view until a while ago. And it was widely believed that arguments for incompatibilism rest on a modal fallacy" (Vihvelin 2003). There's something to the thought that incompatibilists are in the same boat with fatalists, even despite the advent of the consequence argument (Wiggins 1973; van Inwagen 1975; Lamb 1977; Ginet 1980), which has been recognised to break the compatibilist hegemony over the problem of free will and determinism (Levy and McKenna 2009). If Westphal (2012) is right, then one popular argument for incompatibilism - van Inwagen's "First Formal Argument" - does rest on a modal fallacy. Similarly, Warfield (2000) claims that the standard modal formulation of the master argument is a modal fallacy.

My aim in this paper is twofold. First, I aim to show that Westphal and Warfield are mistaken. Even so, I think that there's something to the thought that incompatibilists are in the same boat with fatalists (though not because they rely on invalid modal arguments). After drawing a lesson from the consequence argument, I will put forward a new argument for fatalism understood as the thesis that we are powerless to do anything other than what we actually do. Actuality, as we shall see, plays a crucial role in my argument. I'm going to argue that there's a striking similarity between the consequence argument and this new ar-

\footnotetext{
${ }^{1}$ See Earman (1986).
} 
gument for fatalism.

Here's the strategy. First, I discuss Westphal's objection to van Inwagen's "First Formal Argument" for incompatibilism and show that the argument is no modal fallacy. Next I turn to Warfield's objection and show how it can be avoided with a fairly uncontroversial principle concerning actuality propositions, that is, propositions of the form "Actually, $p$ ". Finally, I show how this strategy may be used to put forward a new argument for fatalism. I conclude with some remarks about the modal formulation of the consequence argument, arguing that the best way to avoid the new fatalist argument is to deny that the meaning of "could have rendered false" captures the relevant sense of "free will".

\section{The "First Formal Argument" is no modal fallacy}

Let's start with Westphal's objection to van Inwagen's first formal argument for incompatibilism, which starts with the following scenario:

JUDGE: Let us suppose there was once a judge who had only to raise his right hand at a certain time, $\mathrm{T}$, to prevent the execution of a sentence of death upon a certain criminal, such a hand-raising being the sign, according to the conventions of the judgeâ $\Theta^{T M} \mathrm{~s}$ country, of a granting of special clemency. Let us further suppose that the judge â $€^{\prime \prime}$ call him $\hat{a} \in^{\sim} J \hat{a} \in^{T M}$ â $€^{\prime \prime}$ refrained from raising his hand at that time, and that this inaction resulted in the criminalâ $\in^{\mathrm{TM}} \mathrm{s}$ being put to death. We may also suppose that the judge was unbound, uninjured, and free from paralysis; that he decided not to raise his hand at $\mathrm{T}$ only after a period of calm, rational, and relevant deliberation; that he had not been subjected to any â $€^{\sim}$ pressureâ $€^{T M}$ to decide one way or the 
other about the criminalâ $\Theta^{T M} \mathrm{~s}$ death. (van Inwagen 1975: 190-1)

In the argument, let $t_{0}$ be filled in by some instant of time earlier than $j \hat{\mathrm{a}} \in^{\mathrm{TM}} \mathrm{s}$ birth. $P_{0}, L$ and $P$, respectively, by a true proposition about the total state of the world at $t_{0}$, the conjunction of all the correct laws of nature and a true proposition that expresses the whole state of the world at $t$. Now the argument (van Inwagen 1983: 70):

1. The truth of determinism entails that the conjunction of $P_{0}$ and $L$ entails $P$.

2. It is not possible that $j$ have raised his hand at $t$ and $P$ be true

3. If 2 is true, then if $j$ could have raised his hand at $t, j$ could have rendered $P$ false.

4. If $j$ could have rendered $P$ false, and if the conjunction of $P_{0}$ and $L$ entails $P$, then $j$ could have rendered the conjunction of $P_{0}$ and $L$ false.

5. If $j$ could have rendered the conjunction of $P_{0}$ and $L$ false, then $j$ could have rendered $L$ false.

6. $j$ could not have rendered $L$ false.

Therefore,

7. If determinism is true, $j$ could not have raised his hand at $t$.

The argument has controversial premises, such as 5 and 6 (see, for instance, Lewis 1981). But (2) was taken to be entirely unproblematic. And that's exactly the premise that Wespthal attacks. He suggests that the argument is somewhat fatalist in spirit, and that the mistake in it is in the reasoning for (2), when modality is introduced. Here's what van Inwagen gives in support of $(2)$ : 
â $€ œ T h e ~ s y m b o l ~ a ̂ € \sim P a ̂ €^{T M}$ is our name for the proposition that expresses the state the world was in fact in at $t$, a time at which $j \hat{\mathrm{a}} \in^{\mathrm{TM}} \mathrm{s}$ hand was not raised. It is therefore impossible for $P$ to be true if $j \hat{\mathrm{a}} \epsilon^{\mathrm{TM}} \mathrm{s}$ hand was raised at $t$, or indeed if things were in any way different at $t$ from the way they actually were.â $€$ (van Inwagen, 1983: 70)

van Inwagen writes that it is impossible for $P$ to be true if [my emphasis] $j \hat{\mathrm{a}} \in^{\mathrm{TM}} \mathrm{s}$ hand was not raised at $t$. Following Westphal I will use the italic capital letter $J$ for the proposition that the judge did raise his hand at $t$, and the italic capital letter $P$ for the proposition denoted by "P".

Westphal argues that either plausible reading of van Inwagen in the argument for (2),

$$
\begin{gathered}
(\mathrm{K}) \sim \diamond(J \supset P) \\
\text { or } \\
\text { (C) } J \supset \sim \diamond P,
\end{gathered}
$$

is false.

Consider $(\mathrm{K})$. If $(\mathrm{K})$ is true, then it follows that $\square J$ and $\square \sim P$. However, it cannot be the case that the conjunction is true. Since $j$ doesn't raise his hand, $\sim J$ is true, and so it follows (assuming a modal system at least as strong as $T$ ) that $\diamond \sim J$, which contradicts $\square J$.

Now consider $(\mathrm{C})$. Westphal argues that the argument for $(\mathrm{C})$ is a modal fallacy. If $J$ is true, it only follows that $\sim P$. It doesn't follow that $P$ cannot be true.

We can see that van Inwagenâ $€^{T M} s$ â $€^{\sim}$ First Formal Argumentâ $\in^{\mathrm{TM}}$ is actually strangely deterministic in spirit. Suppose that, counterfactually, the judge, moved by the quality of mercy, did raise his hand, which is surely a possible event. In that event $j$ would generate 
a possible world in which, according to van Inwagen, the entire actual present was fixed and unalterably not the (counterfactual) present, because, by $\mathrm{C}, \sim \diamond p$ was true, and so $\square \sim p$ was true. In that not-so-distant possible world, it was impossible for the judge not to show mercy in our actual world! (Westphal 2012: 39)

Like Westphal, I think there's some fatalist reasoning behind the argument. However, this reasoning is no modal fallacy. So let me argue, first, why I think the reason for (2) is no modal fallacy. I'll come back to the other point later.

Westphal thinks that van Inwagen genuinely meant to assert $J \supset \sim \diamond P$. I do not agree with him. Instead I contend that there is a more charitable way to understand the argument for (2).

First, van Inwagen could just have said that (2) is conceptually true. What the expression "it is therefore impossible for $\mathrm{P}$ to be true if $j$ 's hand was not raised" means in English is that it is impossible for $P$ to be true and $j$ 's hand to be raised at $t$. If Westphal's point is that van Inwagen used the wrong connective, then one might just say that this is no modal fallacy but a careless way to state a necessary truth. In that case, he should have written:

$\left(2^{*}\right)$ â $€ œ I t$ is impossible for $P$ to be true and [my emphasis] $j \hat{a} \Theta^{T M} \mathrm{~s}$ hand to be raised at $t$.â $€$

That is, $\left(2^{*}\right)$ should be read as:

$$
\left(2^{*}\right) \sim \diamond(P \wedge J)
$$

This is a necessary truth that falls out of the definition of "P". $P$ is a proposition that describes the whole state of the world at $t$, one that includes $j$ not raising his hand. That is, necessarily, if $P$ is true, then $j$ does not raise his hand.

$$
\left(3^{*}\right) \square(P \supset \sim J)
$$


Of course, $\left(3^{*}\right)$ is equivalent to $\left(2^{*}\right)$. Thus, it is impossible for $P$ to be true and $j \hat{a} \in^{T M} \mathrm{~s}$ hand to be raised.

This is the correct argument for the second premise of van Inwagenâ $\in^{\mathrm{TM}} \mathrm{s}$ first formal argument, and it is entirely unproblematic ${ }^{2}$. (On top of that, in the first sentence of the paper Westphal claims: â $€$ @ believe that the argument given by Peter van Inwagen for the second premiss in his $\hat{a} €^{\sim}$ First Formal Argumentâ $€^{T M}$ (van Inwagen 1983: 70) is invalid, and that accordingly the entire â $€^{\sim}$ First Formal Argumentâ $€^{\text {TM }}$ is unsoundâ€ (Westphal 2012: 36). Even if, counterpossibly, the argument for the second premise was invalid, which it canâ $\in^{T M} t$ be since the conclusion is a necessary truth, it would not follow that the second premise is false, so it would not follow that the argument is not sound.)

Though Westphal is mistaken, I believe his arguments against van Inwagenâ $\Theta^{T M}$ s presumed motivations for $J \supset \sim \diamond P$ have a point. As Westphal suggests, there's something strangely "deterministic in spirit" in the argument, that "it was impossible for the judge not to show mercy in our actual world" (39). The claim that it's impossible for the judge not to show mercy in our actual world is - I think - true, though not because of determinism. What generates the problem is actuality. How so?

Let's go back to the judge scenario, and consider the

\footnotetext{
${ }^{2}\left(2^{*}\right)$ allows one to avoid the charge of modal fallacy, and it is compatible with Westphal's understanding of premise (2). However, the premise as stated in the original argument (in 1975) is not a conjunction, but a conditional (van Inwagen 1975: 191):

(2) If $j$ had raised his hand at $t, P$ would be false.

Since $\left(2^{*}\right)$ is true, it follows that, necessarily, if $j$ raises his hand at $t$, then $P$ is false, that is, $\square(\mathrm{J} \supset \sim P)$. So it follows that if $j$ had raised his hand at $t, P$ would be false, simply because the strict conditional implies the counterfactual one. Thus, premise (2) as originally formulated is true too.
} 
sentence " $j$ didn't raise his hand at $t$ ". The move here is that this sentence can be rigidified with the actuality operator. Syntactically, we can combine the sentence with actually to get the more complex sentence "Actually $j$ didn't raise his hand at $t$ ". Semantically, the complex sentence expresses a proposition that is true at an arbitrary possible world iff in the actual world $j$ didn't raise his hand at $t$, which is - we are supposing - true. Now, it should be obvious that whenever a sentence $S$ is true, the more complex sentence "Actually $S$ " is necessarily true. Thus, the sentence "Actually $j$ didn't raise his hand at $t$ " expresses a proposition that is necessarily true. In other words, I am just appealing here to the following scheme (where "@" stands for the actuality operator):

$$
\text { (@) @ } \varphi \rightarrow \square @ \varphi \text {. }
$$

Any normal modal logic with @ validates the above scheme (Crossley and Humberstone 1977; Hazen 1976, 1978).

When van Inwagen introduced the expression "could have rendered false", he claimed that we are powerless to render propositions that are necessarily true false. Take the proposition that $27 \times 15=405$, for instance (van Inwagen 1983: 66). It seems plausible that we cannot render that proposition false because we cannot render false propositions that are necessarily true. Well, the proposition expressed by “Actually $j$ didn't raise his hand at $t$ " is one of them, for it's necessarily true. So, given the assumption that $j$ didn't raise his hand in our actual world, it does follow - as Westphal suggests - that it's impossible for him not to show mercy in our actual world.

Even though there's no modal fallacy involved here, the way van Inwagen interprets "could have rendered false" does suggest that the argument is somewhat fatalist in spirit. For any sentence $S$ concerning human 
action, we can always form the more complex sentence "Actually S", which expresses a necessarily true proposition. Given the standard meaning of "could have rendered false" $"$, it follows that no one could have rendered false the proposition expressed by "Actually $S$ ".

This fairly simple point concerning actuality has important consequences for the third formal argument as well. As I shall argue, we can get a similar fatalist conclusion with respect to van Inwagen's third formal argument. And just like with the first formal argument, we can show that there's no modal fallacy involved in it, contrary to Warfield's claim. Let's then move on and consider Warfield's objection.

\section{Warfield's modal fallacy objection}

Warfield's objection is directed to van Inwagen's third formal argument for incompatibilism. This argument makes use of a sentential operator $\mathbf{N} \varphi$, which is read in English as " $\varphi$ and no one has, or ever had, any choice about whether $\varphi$ " (van Inwagen 1983: 93-95). Now, let $L$ stand for the conjunction of the laws of nature and $P_{0}$ for a true proposition about the whole state of the world in the distant past. The argument runs as follows:

\section{$(\alpha) \square \phi \vdash \mathbf{N} \phi$}

$(\beta) \mathbf{N} \phi, \mathbf{N}(\phi \supset \psi) \vdash \mathbf{N} \psi$

(1) $\square\left(\left(L \wedge P_{0}\right) \supset P\right)[$ Determinism]

(2) $\square\left(L \supset\left(P_{0} \supset P\right)\right)$ [modal logic]

(3) $\left.\mathbf{N}\left(L \supset\left(P_{0} \supset P\right)\right)[\alpha, 2)\right]$

(4) $\mathbf{N} L$. [Premise]

${ }^{3}$ That is, $s$ can render $p$ false iff $s$ can do something such that, if $s$ were to do it, $p$ would be false. 
(5) $\mathbf{N} P_{0}$ [Premise]

(6) $\mathbf{N}\left(P_{0} \supset P\right)[\beta, 3,4]$

(7) $\mathbf{N} P[\beta 5,6]$

Warfield has objected to it by pointing out that, as long as it is an argument for incompatibilism, it needs to be an argument for the claim that determinism strictly implies $\mathbf{N} P$. Consider:

(2) If determinism is true, then $\mathbf{N} P$.

(2) is supposed to be incompatibilism, the view that determinism and free will are incompatible. But what's the meaning of "if-then" in (2)? Warfield's point is that if by "if-then" we mean the material conditional, then (2) is not a thesis that may be properly called "incompatibilism". (2) understood in terms of the material conditional does not establish the incompatibility of free will and determinism, for this claim - if true - is merely contingently true.

Now, if (2) is a thesis that may be properly called "incompatibilism", then a better way to understand it is in terms of the strict implication. That is, rather than being an argument for

(Weak) If determinism is true, then $\mathbf{N} P$,

where the "if-then" of (Weak) does not have the force of the strict implication, it should be an argument for

(INC) Necessarily, if determinism is true, then $\mathbf{N} P$.

As Warfield correctly notices, (INC) does not follow from the premises if they are contingently true:

Most incompatibilists, to be precise, seem unaware that in order to get the incompatibilist conclusion that determinism and freedom are 
strictly incompatible (that no deterministic world is a world with freedom), their conditional proofs must not introduce or in any way appeal to premises that are merely contingently true in between the assumption of determinism and the step at which the â€œno freedomâ $€$ conclusion is reached. (Warfield 2000: 169)

Nonetheless, there's a simple reply to the modal fallacy objection if we use any simple background modal logic, as weak as $\mathbf{K}$, containing $\mathbf{N}$, plus an actuality operator, @, in the language. Let's say that the modal argument merely establishes (Weak), and let $D$ stand for the claim that determinism is true. One might argue as follows:

(1) @( $D \supset \mathbf{N} P) .[$ Weak]

$(2) @(D \supset \mathbf{N} P) \rightarrow \square @(D \supset \mathbf{N} P)$. [Axiom of $\mathbf{K}+$ a]

(3) $\square @(D \supset \mathbf{N} P)$. [From (1) and (2)]

Provided Warfield's point is that the modal argument doesn't establish incompatibilism because it merely establishes a contingent claim, that the truth of determinism materially implies that there's no free will, the above strategy solves the problem. While the material conditional is just contingently true, (3) is true in all the possible worlds. So, if Warfield's point is that (Weak) doesn't establish incompatibilism because it's a contingent claim, then one can simply claim that the modal argument is an argument for the claim that, in the actual world, if determinism is true, there is no free will ${ }^{4}$. So, as long as the modal argument is an argument for (3), it's no modal fallacy.

\footnotetext{
${ }^{4}$ Or this: the argument establishes incompatibility in worlds "like ours", where $N L$ and $N_{P} 0$ hold. Thanks to an anonymous referee for pointing this out.
} 
You could object that (3) doesn't represent a thesis that may be properly called "incompatibilism". After all, it doesn't establish the claim that every deterministic world is a world without freedom. But I would like to question that for a moment. When talking about free will, we want to know whether there is free will in the actual world. The claim that the truth of determinism rules out free will in our world is a legitimate and interesting one. If there is no free will in the actual world (given the truth of determinism), why should one think that there might other distant possible worlds where deterministic agents are free? Unless, of course, the distant worlds are worlds where agents are relevantly different from us. While we care about our intuitions in quite distant possible worlds, we care more about our intuitions with respect to the actual world. If the modal argument were to give the wrong result for the actual world, we would definitely have a problem. But it doesn't seem to. At least from the point of view of the actual world, agents relevantly like us don't have the power to change the past or break the laws of nature.

In fact, two recent objections to the modal argument don't say anything about agents relevantly like us. Campbell (2007) argues that $\mathbf{N} P_{0}$ isn't necessarily true because there are worlds without a past, worlds where agents exist from the first moment of time. Similarly, Cutter (2017) argues that $\mathbf{N} L$ isn't necessarily true because there are worlds where some bizarre creatures can break the laws of nature. As long as the argument is an argument for (3), both objections are beside the point. But notice that the premises can be read as necessarily true too, as long as the claim is that, at the actual world, no one has any choice about the truth of $P_{0}$ and $L$; after all, @N $L$ and $@ \mathbf{N} P_{0}$ are both necessarily true, given the axiom of $\mathbf{K}+@$. Again, there's no modal fallacy in the argument. 
The crucial step of my reply is (2). You might point out that, if we accept that actuality is necessary, we won't have any choice about propositions which are actually true. And this is totally right. If this is strategy goes through, then we can surely put forward an argument for fatalism understood as the claim that we are powerless to do other than what we actually do.

What's going on here, I suggest, is a puzzle between actuality, $\mathbf{N}$ and the meaning of "could have rendered false". My aim in the next section is to make this puzzle explicit, and suggest a solution to it.

\section{A new argument for fatalism}

Let me go back to Westphal's claim that, in the judge scenario, it was impossible for the judge not to show mercy in our actual world. I suggested that one can get a fatalist thesis from actuality and the meaning of "could have rendered false", thus showing that Westphal is right in claiming that it was impossible for the judge not to show mercy in our actual world. My aim in this section is to formulate this argument in a more explicit way.

(RF) $s$ can render $P$ false iff $s$ can do something such that, if she were to do it, $P$ would be false

Now consider fatalism:

(Fatalism) the view that we are powerless to do anything other than what we actually do (Rice 2014).

Finally, we have the axiom $\mathbf{K}+@$ :

\section{(Actuality) @ $\phi-3 \square @ \phi$}

We have all the ingredients to put forward an argument for fatalism. Let @ $P$ stand for any true proposition about an actual human action, such as the proposition that the judge does not show mercy in our actual 
world. We can easily show that no one can render @ $P$ false, including the judge. If $@ P$ is true, then given actuality, it follows that $\square @ P$ is true. And given the standard meaning of "could have rendered false", it follows that $\mathbf{N} @ P$. In a more schematic form, the new fatalist argument runs as follows:

(1) @P. [Premise]

(2)@P $\rightarrow \square @ P$. [Axiom of $\mathbf{K}+@]$

(3) $\square @ P$. [From (1) and (2)]

(4) $\mathbf{N} @ P$. [From $(3)$ by $(\alpha)]$

Like van Inwagen, I'm happy to state the free will thesis as a thesis about agents and propositions (van Inwagen 1983: 66). This is why the phrase "could have rendered false" was introduced as a technical jargon. It's a way to describe our powers to act and modify the world as powers over the truth-values of propositions. (4) nicely captures the claim that we are powerless to do anything other than what we actually do. If power over the truth-value of a proposition is the ability to render this proposition false, then we have no power about the truth-value of propositions that are actually true. The argument is surely valid. But is it cogent?

One option is to reject (2). But why should one reject it? Notice that the main motivation for (2) is to formalise modal discourse in English, which is something, by and large, independent of motivations with respect to the free will problem. (2) is valid in any normal modal logic equipped with @ and an orthodox possible worlds semantics (see, for instance, Hazen (1976), Crossley and Humberstone (1977), Cresswell (1990)). While there's independent motivation for accepting (2), the only motivation I can see to reject it is the denial of (4). That is, one might say that (4) is too implausible, so that we have to reject (2). However, this is precisely what's at stake here. The fatalist 
argument is an argument for the claim that we cannot do otherwise from what we actually do. We cannot simply reject (2) because we don't want to accept the proposition that follows from it.

Another option is to reject fatalism as the thesis that we are powerless to do anything other than what we actually do. One thing is to say that no can render @ $P$ false. Another thing is to say that no one can render $P$ false. All that the new fatalist argument shows is the former claim, not the latter. Since actuality is doing all the work in the argument, we might just accept the conclusion that no can render false propositions that are actually true. In other words, a fatalist argument has to show that $\mathbf{N} P$, not $\mathbf{N} @ P$.

Even so, it's not clear how one may have a choice regarding $P$, but not $@ P$. The power one exercises regarding the fact that $P$ is not different from that regarding @ $P$. When these facts obtain, one has the same powers, abilities, mental states and the like. It seems that there's nothing about the agents themselves that would explain a difference regarding one having a choice about $P$ and $@ P$. Whatever grounds the truth of $P$, such as a free action, should also ground the truth of $@ P$. To be sure, I'm not the first to suggest something like this. Ginet proposes something analogous.

Suppose that is is now in my power to make it the case that $p$. Then it is now in my power to make the actual world contain the fact that $p$. (Ginet 1990: 103, footnote 3)

So, if it's not in your power to make the actual world contain the fact that $P$ - because it is not in your power to make the actual world to be different than what it is - then it it's not in your power to make it the case that $P$.

I have presented the new fatalist argument in an 
analogous way to the consequence argument, but it needn't be. Another way to see the worry is to consider a different incompatibilist argument, such as the addition argument (Pike 1977; Ginet 1990; Warfield 2003; Haji 2009). The core idea here may be expressed by Ginet's words that "freedom is freedom to add to the given past" (Ginet 1990: 103). That is, necessarily, someone acts freely only if her doing otherwise is a consistent addition to the past and laws of nature. However, given determinism, any non-actual event is an inconsistent addition to the past and laws of nature. So, if determinism is true, no one acts freely.

The trick of this argument is that determinism reduces modal space, in the nomological sense, quite a lot. If the truth of a proposition obtains in a deterministic world, it obtains exclusively at one nomologically possible world. It's not nomologically possible for the truth of that proposition not to obtain. Actuality does a similar job by reducing modal space to one possible world. The truth of @P obtains exclusively at one world, which is the actual one. Just like, given determinism, there's no consistent addition to the past and laws of nature, given the actual world, there's no consistent addition to the way things actually are. If this is necessary for free will, then there's no such as thing as free will.

The upshot is that, if actuality is necessary, and we accept the meaning of "could have rendered false", we have no choice about propositions that are actually true. Yet, you could say that it seems quite implausible that, at the actual world, no one has free will. I myself think it would be bad news if the new fatalist argument were sound. Perhaps there's something wrong with the argument. But what's exactly wrong with it?

Maybe the fatalist argument fails for reasons I presented before $^{5}$ : how one may have a choice regarding

\footnotetext{
${ }^{5}$ Thanks to an anonymous referee for raising this point.
} 
$P$ but not @P? After all, there is nothing about the agent that would explain the difference. The only plausible answer is given by the meaning of "rendering $\mathrm{p}$ false": that is, whether $s$ can render $p$ false depends on there being a world in which $s$ does something different and $p$ is false. So, here is a suggestion. Perhaps the meaning of "could have rendered false" doesn't capture the relevant meaning of "free will", contrary to what van Inwagen suggested. If you cannot render a proposition false, this doesn't mean you don't have free will. What I'm proposing is that free will has more to do with the sourcehood approach than to alternative possibilities. For example, suppose that you're the appropriate source of the truth of a proposition that is metaphysically necessary. If this proposition is metaphysically necessary, you cannot render it false. Even so, there's a legitimate sense in which you are free, one in which the truth of the proposition obtains in virtue of what you do.

Think of this suggestion as somewhat analogous to Fine's (1994) idea that the concept of an essential property cannot be properly captured in terms of possible worlds analyses. Socrates has the property of belonging to the singleton Socrates in all the possible worlds he exists. But this doesn't seem essential to Socrates. The singleton's existence depends on Socrates, but Socrates' existence doesn't depend on the singleton. Likewise, my suggestion is that the concept of free will is more fine-grained than possibleworld analyses such as that of "could have rendered false". If @ $P$ is the proposition that you actually decide to read this paper, and the truth of this proposition depends on your deciding to read this paper, then you have a choice about it, even though you cannot render it false.

If the above is correct, then the claim that $\mathbf{N} @ P$ for any proposition about human action - is true. In 
fat, if you accept a modal system as strong as $\mathrm{S} 4$, then it's necessarily true. Nevertheless, accepting the conclusion doesn't boil down to accepting that we aren't free agents. We can even state the free will thesis as a thesis about agents and propositions. But you can have power over the truth-value of a proposition without having the ability to render it false. Thus, if we accept a more fine-grained interpretation of "no choice about", rule $(\alpha)$ will fail! How that interpretation would be? Well, here is a suggestion: if your performing an action grounds the truth $p$, then you have a choice about whether $p$ is true (see Raven (2015) for a survey of the main debates on grounding). The upshot is that if the new fatalist argument fails to establish the claim that there's no free will, so does the consequence argument.

\section{Conclusion}

I have argued that Westphal's recent objection to the first formal argument fails. Since the second premise is a necessarily true proposition, it doesn't matter whether the argument for it is a modal fallacy. Yet, I used Westphal's idea about van Inwagen's presumed motivations for the second premise to reply to Warfield's modal fallacy objection. And it turns out that there's a puzzle with respect to actuality and the meaning of "could have rendered false". If we accept both actuality and $(\mathrm{RF})$, then we have an easy argument for fatalism. My suggested solution to it was to deny that the ability to render a proposition false is relevant to the meaning of "free will".

So, in a way, fatalism isn't that bad. If free will doesn't have to do with the ability to render a proposition false, then fatalism isn't a threat to free will. Similarly, if one thinks that free will doesn't require the ability to do otherwise, then the thesis that no one 
is able to act otherwise than one in fact does isn't a threat to free will either. Whether my proposal is to be taken as an argument for fatalism, or as an argument against the consequence argument, is something I'll leave you to decide.

\section{References}

Campbell, J. K., 2007. "Free Will and the Necessity of the Past." Analysis, 67(2): 105-111. doi:10.1093/analys/67.2.105

Cresswell, M., 1990. Entities and Indices. Dordrecht: Kluwer Academic Publishers.

Crossley, J. N. and Humberstone, L, 1977. "The logic of 'actually"'. Reports on Mathematical Logic 8: 11-29.

Cutter, B., 2017. "What is the consequence argument an argument for?", Analysis 77 (2): 278:287.

Fine, K., 1994, "Essence and Modality: The Second Philosophical Perspectives Lecture", Philosophical Perspectives, 8: 1-16.

Ginet, C., 1983. "In Defense of Incompatibilism." Philosophical Studies, 44: 391-400.

Ginet, C., 1990. On Action. Cambridge: Cambridge University Press.

Haji, T., 2009. Incompatibilism's Allure. Buffalo: Broadview Press.

Hazen, A. P., 1976. "Expressive completeness in modal language." Journal of Philosophical Logic, 5:25-46. 
Lamb, J., 1977. "On a Proof of Incompatibilism." The Philosophical Review, 86: 20-35.

Levy, N. and McKenna, M., 2009. "Recent Work on Free Will and Moral Responsibility", Philosophy Compass 4 (1): 96-133.

Raven, M., 2015. "Ground", Philosophy Compass 10 (5): 322-33.

Lewis, D. 1981. Are We Free to Break the Laws?, Theoria 47: 113-21

Rice, H., 2014. "Fatalism", Retrieved from: https://plato.stanford.edu/entries/fatalism/.

Van Inwagen, P., 1975. "The Incompatibility of Free Will and Determinism." Philosophical Studies, 27: 185-199.

Van Inwagen, P., 1983. An Essay on Free Will, Oxford: Clarendon Press.

Vihvelin, K., 2003. "Arguments for incompatibilism", Retrieved from: https://plato.stanford.edu/entries/incompatibilismarguments/.

Warfield, T., 2000. "Causal determinism and human freedom are incompatible: a new argument for incompatibilism", Philosophical Perspectives 14: $167-80$.

Warfield, T., 2003. "Compatibilism and Incompatibilism: Some Arguments." in The Oxford Handbook of Metaphysics. Michael Louxand Dean Zimmerman (eds.), Oxford: Oxford University Press, 613-630.

Westphal, J., 2012. "Is There a Modal Fallacy in van Inwagen's 'First Formal Argument'?", Analysis 72 (1): 36-41. 
From modal fallacies to a new argument for fatalism 107

Wiggins, D., 1973. "Towards a reasonable libertarianism." In T. Honderich (ed.) Essays on Freedom of action. Boston: Routledge and Kegan Paul, pp. 43-44.

Manuscrito - Rev. Int. Fil. Campinas, v. 42, n. 3, pp. 86-107, Jul.-Sep. 2019. 